\title{
Intra-arterial cisplatin for the treatment of malignant gliomas
}

\author{
Herbert B. Newton, Michaelyn A. Page, Larry Junck and Harry S. Greenberg \\ Department of Neurology, University of Michigan Hospitals, Ann Arbor, MI 48109 USA
}

Key words: malignant glioma, intra-arterial, cisplatin treatment, regional advantage

\begin{abstract}
Summary
Cisplatin (DDP) is a chemotherapeutic agent that has shown efficacy against primary CNS malignancies. Intraarterial (IA) administration of DDP to patients with brain tumors should produce higher peak levels of drug than intravenous (IV) administration of an identical dose and reduce systemic toxicity. Twelve patients with malignant glioma were entered into the study. All had failed irradiation, 11 had failed IA BCNU. Each patient received IA DDP, $58-100 \mathrm{mg} / \mathrm{m}^{2}$, into the internal carotid artery at four to six week intervals. One of $12 \mathrm{pa}$ tients had a partial response of 6 months. The remaining 11 patients had progressive disease [10] or severe complications [1]. Toxicity included seizures in four patients, weakness and/or aphasia in four patients, coma in two patients, and visual deterioration in two patients. IA DDP has very limited efficacy in patients with malignant gliomas after failure of nitrosoureas and is associated with an unacceptable level of toxicity. IA DDP may be more effective when used as initial chemotherapy of malignant gliomas.
\end{abstract}

\section{Introduction}

Primary central nervous system (CNS) malignancies continue to have a high mortality. Approximately one-half of these cases are malignant gliomas which are classified as glioblastoma multiforme (Kernohan's grade IV) and anaplastic astrocytoma (Kernohan's grade III) [1]. Malignant gliomas are uniformly fatal tumors. Studies by the Brain Tumor Study Group [2] have shown a median survival of 17 weeks in patients who have received only surgical resection. Survival was extended to a median of 37 weeks with radiation therapy (RT). The additional of singleagent chemotherapy has improved long term survival to a limited extent. BCNU, when used after resection and RT, improved the median survival to 51 weeks [3] in one trial and 50 weeks in another [4].

In recent years newer methods of administration have been sought. Craft et al. [5] compared ${ }^{14} \mathrm{C}$ labelled BCNU given IV and IA in monkeys and found IA administration produced a four-fold higher brain drug level than IV administration of the same dose. These and subsequent studies suggested that IA administration could potentially reduce systemic toxicity [6]. Cisplatin (cisdichlorodiammineplatinum; DDP) is an inorganic complex formed by an atom of platinum (II) surrounded by chlorine and ammonia atoms in the cis position of the horizontal plane. DDP has antitumor effect in a wide variety of neoplasms, especially testicular [7], bladder [8], ovarian [9], and head and neck tumors [10]. The mode of action of DDP appears to be direct binding to DNA, forming intrastrand and interstrand cross links between guanine residues [11].

DDP has also been shown to be effective against primary CNS malignancies. Initial studies by Kahn et al. [12] and Levanthal and Freeman [13] using IV DDP were encouraging. Stewart et al. [14] studied IA administration of DDP in patients with glioblastoma multiforme and metastatic tumors. Six of their 10 evaluable patients responded to treatment. They were able to demonstrate that IA infusion of DDP $\left(60 \mathrm{mg} / \mathrm{m}^{2} \mathrm{q} 6 \mathrm{wks}\right)$ via transfemoral selective inter- 
al carotid artery catheterization was technically feasible and capable of producing tumor regression or stabilization. Subsequent studies using IA DDP have also shown encouraging results against primary CNS tumors [15-18]. This report describes our experienc using IA DDP in the treatment of patients with malignant gliomas.

\section{Materials and methods}

Twelve patients were entered into the study. Patient characteristics are listed in Table 1. Prior to entry all patients had had at least one subtotal resection, and all had pathological confirmation of their diagnosis. Nine patients had glioblastoma multiforme or anaplastic astrocytoma (grade III or IV astrocyto$\mathrm{ma}$ ). The remaining patients had gliosarcoma, grade II/III astrocytoma/oligodendroglioma, and ependymoma, respectively. These tumors were all unilateral and confined to the left or right internal carotid arterial distribution. The average age was 43 years with a range of 11-62 years. All patients had received between 5400-6600 rads of radiation prior to this study. Eleven of 12 patients had received prior chemotherapy. All 11 had received IA BCNU. Two had received continuous infusion of IA dichloromethotrexate (DCMTX). One each had received IA diaziquone (AZQ), continuous IA flourodeoxyuridine (FUdR), and IV dacarbazine (DTIC). One patient also received vincristine and procarbazine. Nine of the 12 patients were taking stable doses of

Table 1. Patient characteristics

\begin{tabular}{ll}
\hline Characteristic & No. patients \\
\hline Total & 12 \\
$\quad$ Sex & \\
$\quad$ Male & 5 \\
$\quad$ Female & 7 \\
Mean age in yrs. (range): & $43(11-62)$ \\
Mean Karnofsky score at entry (range): & $80(50-90)$ \\
Prior chemotherapy & \\
BCNU & 11 \\
DCMTX & 2 \\
Other & 4 \\
None & 1 \\
\hline
\end{tabular}

dexamethasone at the time of entry into the study. Doses ranged from 2 to $16 \mathrm{mg} /$ day, with an average dose of $8 \mathrm{mg} /$ day. Each patient showed evidence of progressive disease by cranial computed tomography (CT) criteria and/or neurologic examination prior to inclusion in this study. Each patient was informed of the investigational nature of the study and signed a consent form.

Pretreatment evaluation consisted of history and physical examination including a complete neurologic examination, Karnofsky rating, and CT scan with and without contrast. CBC with differential, platelet count, electrolytes, BUN, creatinine, creatinine clearance, SGOT, alkaline phosphatase, and LDH were obtained. Baseline audiograms were performed on all patients.

During treatment each patient had weekly CBC with differential and platelet counts. Bimonthly each patient received a neurologic examination and Karnofsky rating. Audiograms were repeated every 12 weeks. The pretreatment laboratory battery was repeated prior to each subsequent treatment.

Prior to administration of IA DDP, each patient received hydration with D5 $0.45 \% \quad \mathrm{NaCL}$ at $150 \mathrm{cc} / \mathrm{hr}$ for 12 hours. Dexamethasone $50 \mathrm{mg}$ IV was given the night before DDP adminstration. It was repeated along with mannitol $12.5 \mathrm{Gm}$ IV the morning of DDP administration. DDP (Bristol Laboratories) was dispensed for IA use in the form of lyophilized powder in $10 \mathrm{mg}$ vials. It was reconstituted for IA use by dissolving $58-100 \mathrm{mg} / \mathrm{m}^{2}$ in 175 to $200 \mathrm{ml}$ of $0.45 \% \mathrm{NaCL}$ solution. Heparin (1000 units) was added to each infusion. The DDP was infused into the left or right internal carotid artery via a catheter placed percutaneously using the femoral approach (10 patients) or through the sideport of an Infusaid permanently implantable intracarotid drug delivery system (manufactured by Shiley Infusaid Corp., Norwood, MA) (2 patients). The Infusaid pump had been implanted prior to entry this study using a technique described by Phillips et al. [19]. An IMED 960 (Medical electronics Corp.) infusion pump was used to infuse DDP through the catheter over one hour. A hyperalimentation filter was in place between the DDP solution and the femoral catheter. In all infusions, the catheter was below the ophthalmic artery. After infusion, each patient 
was hydrated with D5 $0.45 \% \mathrm{NaCL}$ at $200 \mathrm{cc} / \mathrm{hr}$ for 12 hours. Urine output was monitored closely. If it dropped below $200 \mathrm{cc} / \mathrm{hr}$, mannitol $12.5 \mathrm{Gm}$ IV was given. Metoclopramide and lorazepam were administered as needed for nausea and vomiting. Treatment was repeated at 4-6 week intervals as long as the patient remained stable or improved and had absolute granulocyte counts greater than 2500 and platelet counts greater than 100000 .

Response criteria were as follows: Complete Response - complete resolution of all abnormalities on CT scan and an improved or normal neurologic examination without steroid medication; Partial Response - a decrease in the size of the measurable mass lesion on CT scan plus a stable or improved neurologic examination on stable or decreasing doses of steroids; Stable Disease - no change in the size of the tumor on CT scan without significant change in neurologic examination on stable or decreasing doses of steroids; Progressive Disease increase in the size of the tumor on CT scan and/or progressive worsening of neurologic function directly attributable to the growth effects of the tumor. The duration of response dated from the onset of treatment until demonstration of disease progression. A complete trial consisted of at least two infusions of DDP. The trial was stopped after one infusion if a patient demonstrated unequivocal progression.

\section{Results}

Twelve patients received a total of 24 IA DDP infusions. Patient response characteristics are listed in Table 2. Eighteen of 24 infusions were at a dosage of $75 \mathrm{mg} / \mathrm{m}^{2}$. Other doses were as follows: one at $58 \mathrm{mg} / \mathrm{m}^{2}$, three at $90 \mathrm{mg} / \mathrm{m}^{2}$, and two at $100 \mathrm{mg} / \mathrm{m}^{2}$. Five patients received one course of DDP, four patients received two courses, two patients received three courses, and one patient received five courses of DDP. The cumulative dosage ranged from 140 to $580 \mathrm{mg}$, with an average of $266 \mathrm{mg}$.

Only one of 12 patients $(8 \%)$ demonstrated a response to IA DDP. There were no complete responders. Patient \#3 who had a left frontoparietal grade II-III astrocytoma/oligodendroglioma, and had not responded to prior BCNU, had a partial response for six months during which time she received three more treatments. After her second treatment with DDP her tumor displayed diminished bulk and mass effect by CT. During that time she was clinically stable. Repeat CT scan subsequently showed slightly increased volume and enhancement. Ten of the remaining 11 patients had progressive disease. Five patients demonstrated both CT and clinical progression. Four patients had stable CT examination but progressed clinically. Clinical progression was manifested by worsening mono-

Table 2. Response characteristics

\begin{tabular}{|c|c|c|c|c|c|c|c|}
\hline Patient & $\begin{array}{l}\text { DDP } \\
\text { dose } \\
(\mathrm{mg})\end{array}$ & $\begin{array}{l}\# \\
\text { treatments }\end{array}$ & $\begin{array}{l}\text { Cumulative } \\
\text { dose (mg) }\end{array}$ & $\begin{array}{l}\text { Overall } \\
\text { response }\end{array}$ & Clinical & $\mathrm{CT}$ & $\begin{array}{l}\text { Time to } \\
\text { failure } \\
\text { (mo) }\end{array}$ \\
\hline 1 & 75 & 2 & 335 & $\mathrm{P}$ & $\mathbf{P}$ & $\mathrm{S}$ & 4 \\
\hline 2 & 75 & 3 & 405 & $\mathrm{P}$ & $\mathrm{P}$ & $\mathrm{S}$ & 4 \\
\hline 3 & 75 & 5 & 580 & $\mathrm{R}$ & $\mathrm{S}$ & $\mathrm{R}$ & 6 \\
\hline 4 & 90 & 3 & 330 & $\mathrm{P}$ & $\mathrm{S}$ & $P$ & 4 \\
\hline 5 & $58 / 75$ & 2 & 245 & $\mathrm{P}$ & $\mathbf{P}$ & $\mathrm{P}$ & 4 \\
\hline 6 & 75 & 1 & 140 & $\mathrm{P}$ & $P$ & $\mathrm{P}$ & 3 \\
\hline 7 & 75 & 1 & 145 & $\mathrm{P}$ & $\mathrm{P}$ & $\mathrm{S}$ & 1.5 \\
\hline 8 & 75 & 1 & 130 & $\mathrm{P}$ & $\mathrm{P}$ & $\mathrm{P}$ & 1.5 \\
\hline 9 & 75 & 2 & 272 & $\mathbf{P}$ & $\mathrm{P}$ & $S$ & 3 \\
\hline 10 & 75 & 1 & 150 & $\mathbf{P}$ & $\mathrm{P}$ & $\mathrm{P}$ & 1 \\
\hline 11 & $75 / 100$ & 2 & 265 & $\mathbf{P}$ & $\mathrm{P}$ & $P$ & 3.5 \\
\hline 12 & 100 & 1 & 200 & $\mathrm{C}$ & $\mathrm{C}$ & $\mathrm{S}$ & $1 ?$ \\
\hline
\end{tabular}

Abbreviations: $\mathbf{R}$ - partial response; S - stable; $\mathrm{P}$ - progression; C - complications 
or hemiparesis in five patients, progressive aphasia in six patients, increased seizure frequency in two patients, and progressive headache in two patients. One patient had a stable clinical exam but had CT progression. The last patient's (patient \#12) tumor was stable by CT criteria but developed complications from the DDP infusion including mental status changes and encephalopathy that progressed to coma. The range of time to treatment failure was one to six months. The average time to treatment failure was 3.0 months.

Toxicity data are listed in Table 3. The most frequent acute toxicity was gastrointestinal. Seven of our twelve patients developed symptoms of nausea and vomiting. These symptoms were transient, clearing after 24 hours, although they did require treatment with antiemetics. Three patients experienced mild myelosuppression with WBC reaching nadirs of 2500,2500, and 2400, respectively. All platelet count nadirs remained above 125000 . None of our patients developed renal toxicity, hypomagnesemia or diminished auditory acuity.

Two patients exhibited retinal toxicity with associated decreased visual acuity of the ipsilateral eye. Patient \#1 complained of pain in his left eye during and after his initial DDP infusion. He subsequently lost visual acuity and became blind in that eye. Ophthalmic examination and fluorescein angiography revealed retinal vasculitis. Patient \#3 had no pain

Table 3. Toxicity

\begin{tabular}{ll}
\hline Type & No. of patients \\
\hline Neurologic & \\
$\quad$ Auditory & 0 \\
Seizures & 4 \\
Motor weakness & 3 \\
Impaired speech & 3 \\
Trigeminal mononeuropathy & 1 \\
Encephalopathy & 2 \\
Coma & 2 \\
Retinal & 2 \\
& \\
Non-neurologic & \\
Nausea, vomiting & 7 \\
Renal & 0 \\
Myelosuppression & 3 \\
Hypomagnesemia & 0 \\
\hline
\end{tabular}

during DDP infusion but developed blurred vision and diminished visual acuity after her second treatment.

The remaining toxicity was referable to the CNS. Three patients had acute seizure activity during infusion of DDP. Patients \#6 and 10 exhibited brief spontaneously resolving simple partial seizures of the arm, and arm and leg, respectively, contralateral to the side of infusion. Patient \#2 developed status epilepticus which progressed to an encephalopathic and then comatose state. She died four weeks after her initial infusion. CT scans during this time were unchanged.

Four patients developed weakness and/or aphasia. Patient \#3 acutely developed expressive aphasia after her second infusion which never completely resolved. Patient \#6 developed an acute complex of signs three days after treatment that included increased hemiparesis, seizure activity, and aphasia. He progressed to an encephalopathic state, followed by coma, which lasted for two weeks. He eventually recovered alertness but was left with a dense right hemiparesis and severe expressive aphasia. Patient \#9 acutely developed aphasia and right arm weakness that resolved after 12 hours. Patient $\# 10$ acutely developed right hemiparesis that never returned to baseline after months of follow-up. One patient developed trigeminal mononeuropathy manifested by numbness of the face ipsilateral to the side of her infusion. This developed after her fourth treatment.

\section{Discussion}

The theoretical advantages of administering a chemotherapeutic agent IA instead of IV have been examined by previous authors $[6,20]$. The regional advantage $R_{d}$ is defined as the ratio of tumor exposure with IA administration to that with IV administration, where exposure is the concentrationtime integral. Assuming linear kinetics of drug distribution and metabolism it can be shown that $R_{d}$ is independent of the rate of drug administration. Assuming clearance by the lungs is negligible:

$$
R_{d}=1+\frac{C L(t b)}{F}
$$


where $F$ is flow in the artery infused $(\mathrm{L} / \mathrm{min})$, and $\mathrm{CL}(\mathrm{tb})$ is the total body metabolic clearance of the drug ( $\mathrm{L} / \mathrm{min})$ [20]. It is apparent from this relationship that $\mathbf{R}_{\mathrm{d}}$ for a given drug can be maximized by low flow in the artery infused and by rapid systemic clearance of the drug. $\mathrm{R}_{\mathrm{d}}$ for BCNU has been measured in squirrel monkeys [21]. IA administration increased the total tissue radioactivity by $2.4-2.7$ and the DNA bound fraction (presumed site of action of $\mathrm{BCNU}$ ) by 2.3-2.7. These values approximate the calculated $R_{d}$ for BCNU in humans of 3.7 based on an internal carotid blood flow of $0.25 \mathrm{~L} / \mathrm{min}$ and a plasma clearance of $0.7 \mathrm{~L} / \mathrm{min}$.

Based on available clearance data for DDP, $R_{d}$ can be calculated. Data from Campbell et al. [22] show a total body clearance rate for DDP of approximately $0.365 \mathrm{~L} / \mathrm{min}$. If unilateral internal carotid artery blood flow is estimated to be $0.25 \mathrm{~L} / \mathrm{min}$, then $R_{d}$ is calculated to be 2.46 . Based on this information, an advantage for IA therapy was postulated and formed the rationale for administering DDP IA in our study. A recent study using positron emission tomography (PET) analysis of DDP adminstration estimated $R_{d}$ to be 2.5 [23]. This measured value closely approximates our calculated value of $\mathbf{R}_{\mathrm{d}}$.

In our study, none of our patients had a complete response. One of 12 had a brief partial response. She had a grade II-III astrocytoma/oligodendroglioma. Recent data from Cairncross and Macdonald [24] suggests that oligodendrogliomas are quite chemosensitive. Her partial response may have been from this fraction of tumor. The efficacy of IA DDP was less than that seen in most other trials of IV [12, 13] or IA [14-18] administered DDP. Our response rate was also considerably less than those obtained with IV BCNU [3, 4]. Possible explanations for our low response rate may be related to the fact that in our study $92 \%$ of our patients had failed IA BCNU therapy. A higher percentage of our patients failed previously chemotherapy than in other studies. The BCNU may have selectively killed clones of cells that would have been sensitive to DDP, allowing repopulation with more resistant cells [25, 26]. In vitro studies comparing cross-resistance between alkylating agents showed significant cross-resistance between BCNU and DDP [27]. It is therefore possible that IA DDP would be more efficacious when used with patients who have not received prior IA BCNU chemotherapy. Ongoing research at our institution does suggest that procarbazine may be an effective agent when used to treat patients after failure of IA BCNU (unpublished data). A further possible explanation for our lack of partial responders may be that our treatment interval was too long. By using shorter intervals, more partial responses may have been seen, but this probably would have resulted in further toxicity. The high pre-treatment doses of dexamethasone used theoretically could have affected the blood-brain barrier and decreased the amount of DDP delivered to the tumor. High pre-treatment doses of dexamethasone could have also increased tumor concentrations of metallothionein (MT), an inducible low molecular weight protein that binds heavy metal compounds, including platinum, and affords resistance to DDP [28, 29]. However, recent in vitro data in rat hepatocytes showed that after initial MT induction by steroids, further increments in dosage or length of treatment did not significantly increase MT concentrations [28]. Therefore, since our patients were on chronic doses of dexamethasone, the effects of additional steroid on MT induction were probably negligible.

We doubt that our response rates were compromised because of the DDP doses administered. Data from several studies showed that at least $60 \mathrm{mg} / \mathrm{m}^{2}$ of IA DDP was adequate to achieve a response [14-16]. All but one of our patients received $75-100 \mathrm{mg} / \mathrm{m}^{2}$ of DDP per dose.

An additional patient not included in our study with metastatic squamous cell carcinoma to the base of skull and parasellar region was an unequivocal responder. She received six treatments with IA DDP at a dose of $75 \mathrm{mg} / \mathrm{m}^{2}$. Clinically she remained stable while CT scan showed shrinkage of her tumor. This partial response lasted for seven months. She then developed increased tumor mass by CT.

The major dose limiting toxicity in our study was neurotoxicity. None of our patients developed severe toxicity of the GI tract, kidneys, or bone marrow. Four of our patients experienced acute seizure activity, one of whom had status epilepticus requiring treatment. Seizures have been reported by other authors, but not as frequently as in our series [15, 30]. Three patients experienced increased mono-or 
hemiparesis. All had large tumors with significant enhancement and surrounding edema. Kapp and Sanford [31] theorize that gliomas, especially if near the internal capsule, could disrupt relatively the blood-brain barrier of nearby normal neural tissue exposing it to toxic concentrations of DDP that could produce dysfunction. Our patients received aggressive post-treatment hydration which could have lead to an exacerbation of vasogenic edema to an already disrupted blood-brain barrier. An alternative explanation is that these acute infusionrelated complications represented thromboembolic events. Two patients each developed encephalopathy progressing to coma. This has also been documented by Feun et al. [15]. One of these patients remained in coma until death while the other recovered after two weeks. The etiology of these catastrophic events and why it affected these patients in a differential fashion is unclear.

To further clarify the CNS toxicity seen in our patients, the role of prior BCNU was evaluated. The patients who had received prior BCNU and did not develop complications had a mean total dose of $981 \mathrm{mg} / \mathrm{m}^{2}$. The mean total dosage in patients who did develop complications was $1066 \mathrm{mg} / \mathrm{m}^{2}$. This is not a significant difference and does not support a correlation between prior BCNU dosage and subsequent development of complications with IA DDP.

A major dose-limiting toxicity in many studies has been retinal toxicity $[15,32]$. In this study, one patient developed a painless decrement in visual acuity after her second treatment. A second patient developed pain and blurring of vision coincident with his initial DDP infusion that progressed to complete blindness. Recent attempts to avoid retinal toxicity by using supraophthalmic infusion techniques although initially promising, may increase CNS toxicity $[17,33]$.

Ototoxicity has been a frequent complication of therapy in some studies $[34,35]$. None of our patients developed ototoxicity. An additional patient with metastatic squamous cell carcinoma, not included in this study, received IA DDP divided between the left carotid and vertebral arteries and developed moderately severe ototoxicity after her fifth treatment. It appears that the large cumulative doses of DDP, as well as infusion of the drug via the posterior circulation, made this patient more vulnerable to ototoxicity. This patient also developed peripheral neuropathy as a consequence of DDP. She received cumulative DDP doses in excess of $375 \mathrm{mg} / \mathrm{m}^{2}$. Thompson et al. [36] have reported that peripheral neuropathy becomes clinically apparent after a cumulative DDP dose of $350 \mathrm{mg} / \mathrm{m}^{2}$. Our study corroborates their threshold dose. Although it is not clear whether the same mechanism is involved, our glioma patient with trigeminal mononeuropathy also had a cumulative DDP dose in excess of $350 \mathrm{mg} / \mathrm{m}^{2}$. All other patients had cumulative doses less than $280 \mathrm{mg} / \mathrm{m}^{2}$ and did not develop peripheral neuropathy.

\section{Conclusion}

IA administration of DDP has very limited efficacy in patients with primary malignant gliomas showing disease progression after proving refractory to nitrosourea therapy. In our study, only one of 12 patients responded to IA DDP treatment. The DDP doses used in our study of $75 \mathrm{mg} / \mathrm{m}^{2}$ or more resulted in an unacceptable level of toxicity, especially to the CNS. However, DDP may prove to be more effective when used as initial therapy.

\section{References}

1. Zulch KJ: Brain tumors: Their biology and pathology. 3rd edition. Springer-Verlag Publ., Berlin, 1986

2. Walker M, Alexander E, Hunt WE, MacCarty CS, Mahaley MS, Mealey J, Norrell HA, Owens G, Ransahoff J, Wilson CB, Gehan EA, Strike TA: Evaluation of BCNU and/or radiotherapy in the treatment of anaplastic glioma. J Neurosurg 49:333-343, 1978

3. Walker M, Green SB, Byar DP, Alexander E, Batzdorf FU, Brooks WH, Hunt WE, MacCarty CS, Mahaley MS, Meayley, Owens G, Ransahoff J, Robertson JT, Shapiro WR, Smith KR, Wilson CB, Strike TA: Randomized comparisons of radiotherapy and nitrosoureas for the treatment of malignant glioma after surgery. N Eng J Med 303:1323-1329, 1980

4. Green SB, Byar DP, Walker MD, Pistenmaa DA, Alexander E, Batzdorf U, Brooks WH, Hunt WE, Mealey J, Odom GL, Paoletti P, Ransohoff J, Robertson JT, Selker RG, Shapiro WR, Smith KR, Wilson CB, Strike TA: Comparisons of carmustine, procarbazine, and high-dose methylprednisolone as additions to surgery and radiotherapy for the treatment of malignant gliomas. Cancer Treat Rep 67:121-132, 1983

5. Crafts DC, Levin VA, Neilson SA: Intracarotid BCNU. A toxicity study in six Rhesus monkeys. Cancer Treat Rep. 60:541-545, 1976

6. Fenstermacher JP, Cowles AL: Theoretic limitation of in- 
tracarotid infusions in brain tumor chemotherapy. Cancer Treat Rep 61:519-526, 1977

7. Einhorn LH, Donohue J: Cis-diamminedichloroplatinum, vinblastine, and bleomycin combination chemotherapy in disseminated testicular cancer. Ann Int Med 87:293-298, 1977

8. Yagoda A, Watson RC, Gonzalez-Vitale JC, Grabstold H, Whitmore WF: Cis-dichlorodiammineplatinum (II) in advanced bladder cancer. Cancer Treat Rep 60:917-923, 1976

9. Wittes RE, Cvitkovic E, Shah J, Gerold FP, Strong EW: Cisdichlorodiammineplatinum (II) in the treatment of epidermoid carcinoma of the head and neck. Cancer Treat Rep 61:359-366, 1977

10. Wiltshaw E, Kroner T: Phase II study of cisdichlorodiammineplatinum (II) in advanced adenocarcinoma of the ovary. Cancer Treat Rep 60:55-60, 1976

11. Lippard SJ: New chemistry of an old molecule: cis (Pt(NH3)2-CL2). Science 218:1075-1082, 1982

12. Khan A, McCollough D, Barts F, Sinks LF: Update on use of cisplatin in CNS malignancies. Proc Am Assoc Cancer Res $21: 390,1980$

13. Levanthal BG, Freeman A: Cis-diamminedichloroplatinum - a phase II study in pediatric malignancies. Proc Am Assoc Cancer Res 20:197, 1979

14. Stewart DJ, Wallace S, Feun L, Leavens M, Young SE, Handel S, Mavligit G, Benjamin RS: A phase I study of intracarotid cis-diamminedichloroplatinum (II) in patients with recurrent malignant intracerebral tumors. Cancer Res 42:2059-2062, 1982

15. Feun LG, Wallace S, Stewart DJ, Chuang VP, Yung WA, Leavens ME, Burgess MA, Savaraj N, Benjamin RS, Young SE, Tang RA, Handel S, Mavligit G, Fields WS: Intracarotid infusion of cis-diamminedichloroplatinum in the treatment of recurrent malignant brain tumors. Cancer 54:794-799, 1984

16. Lehane DE, Bryan RN, Horowitz B, DeSantos L, Ehni G, Zubler MA, Moiel R, Rudolph L, Aldama-Leubbert A, Mahoney D, Harper R: Intra-arterial cisplatinum chemotherapy for patients with primary and metastatic brain tumors. Cancer Drug Delivery 1:69-77, 1983

17. Kapp JP, Vance RB: Supraophthalmic carotid infusion for recurrent glioma: rationale, technique, and preliminary results for cisplatin and BCNU. J Neuro-oncol 3:5-11, 1985

18. Vance RB, Kapp JP: Supraophthalmic carotid infusion with low dose cisplatin and BCNU for malignant glioma. J Neurooncol 3:287-290, 1986

19. Phillips TW, Chandler WF, Kindt GW, Ensminger WD, Greenberg HS, Seeger JF, Doan KM, Gyves JW: New implantable continuous administration and bolus dose intracarotid drug delivery system for the treatment of malignant gliomas. Neurosurgery 11:213-218, 1982

20. Eckman WW, Pattack CS, Fenstermacher JD: A critical evaluation of the principles governing the advantages of IA infusion. J Pharmacokinet Biopharmacokinet 2:257-285, 1974

21. Levin VA, Kubra PM, Freeman-Dove MA: Pharmacokinetics of intracarotid artery ${ }^{14} \mathrm{C}-\mathrm{BCNU}$ in the squirrel monkey. $\mathrm{J}$ Neurosurg 48:587-593, 1978
22. Campbell TL, Howell SB, Pfeifle CE, Wung WE, Boostein $\mathrm{J}$ : Clinical pharmacokinetics of intra-arterial cisplatin in humans. J Clin Oncol 1:755-762, 1983

23. Rottenberg DA, Dhawan V, Cooper SC, Strother SC, Alcock N, Ginos JZ: Assessment of the pharmacologic advantage of intra-arterial versus intravenous chemotherapy using Ncisplatin and positron emission tomography (PET). Neurology $37(\mathrm{~S} 1): 335,1987$

24. Cairncross JG, Macdonald DR: Successful chemotherapy for recurrent malignant oligodendroglioma. Ann Neurol 23:360-364, 1988

25. Yung WKA, Shapiro JR, Shapiro WR: Heterogeneous chemosensitivies of subpopulations of human glioma cells in culture. Cancer Res 42:992-998, 1982

26. Schnipper LE: Clinical implications of tumor cell heterogeneity. N Engl J Med 314:1423-1430, 1986

27. Teicher BA, Cucchi CA, Lee JB, Flatow JL, Rosowsky A, Frei E: Alkylating agents: In vitro studies of cross-resistance patterns in human cell lines. Cancer Res 46:4379-4383, 1986

28. Bracken WM, Klaassen CD: Induction of metallothionein by steroids in rat primary hepatocyte cultures. Tox Appl Pharm 87:381-388, 1987

29. Endresen L, Schjerven L, Rugstad HE: Tumours from a cell strain with a high content of metallothionein show enhanced resistance against cisdichlorodiammineplatinum. ACTA Pharm Toxicol 55:183-187, 1984

30. Bermann IJ, Mann MP: Seizures and transient cortical blindness associated with cisplatinum (II) diamminedichloride (PDD) therapy in a 30-year-old man. Cancer 45:764-766, 1980

31. Kapp JP, Sanford RA: Neurological deficit after carotid infusion of cisplatin and 1,3-bis(2-chloroethyl)-1-nitrosourea (BCNU) for malignant glioma: an analysis of risk factors. Neurosurgery 19:779-783, 1986

32. Wilding G, Caruso R, Lawrence TS, Ostchega Y, Ballintine EJ, Young RC, Ozols RF: Retinal toxicity after high-dose cisplatin therapy. J Clin Onc 12:1683-1689, 1985

33. Kapp JP, Ross RL, Tucker EM: Supraophthalmic carotid infusion for brain tumor chemotherapy. J Neurosurg 58:616-618, 1983

34. Granowetter L, Rosenstock JG, Packer RJ: Enhanced cisplatinum neurotoxicity in pediatric patients with brain tumors. J Neuro-oncol 1:293-297, 1983

35. Reddell RR, Kefford RF, Grant JM, Coates AS, Fox RM, Tattersall MHN: Ototoxicity in patients receiving cisplatin. Importance of dose and method of drug administration. Cancer Treat Rep 66:19-23, 1982

36. Thompson SW, Davis LE, Kornfeld M, Hilgers RD, Standefer JC: Cisplatin neuropathy: clinical, electrophysiology, morphologic, and toxicologic studies. Cancer 54:1269-1275, 1984

Address for offprints: $\mathrm{H}$. S. Greenberg, Department of Neurology, 1914/0316 Taubman Center, University of Michigan Hospitals, Ann Arbor, MI 48109-0316, USA 